\title{
Article
}

\section{'We make them feel special': The experiences of voluntary sector workers supporting asylum seeking and refugee women during pregnancy and early motherhood}

Balaam, Marie-Clare, Kingdon, Carol, Thomson, Gillian, Finlayson, Kenneth William and Downe, Soo

Available at http://clok.uclan.ac.uk/13590/

Balaam, Marie-Clare ORCID: 0000-0003-4511-7352, Kingdon, Carol ORCID: 0000-0002-5958-9257, Thomson, Gillian ORCID: 0000-0003-3392-8182, Finlayson, Kenneth William ORCID: 0000-0002-1287-7630 and Downe, Soo ORCID: 0000-0003-2848-2550 (2016) 'We make them feel special': The experiences of voluntary sector workers supporting asylum seeking and refugee women during pregnancy and early motherhood. Midwifery, 34 . pp. 133-140. ISSN 02666138

It is advisable to refer to the publisher's version if you intend to cite from the work. http://dx.doi.org/10.1016/j.midw.2015.12.003

For more information about UCLan's research in this area go to http://www.uclan.ac.uk/researchgroups/ and search for < name of research Group>.

For information about Research generally at UCLan please go to http://www.uclan.ac.uk/research/

All outputs in CLoK are protected by Intellectual Property Rights law, including Copyright law. Copyright, IPR and Moral Rights for the works on this site are retained by the individual authors and/or other copyright owners. Terms and conditions for use of this material are defined in the policies page. 
"We make them feel special"

\section{We make them feel special": the experiences of voluntary sector workers supporting asylum seeking and refugee women during pregnancy and early motherhood}

\section{INTRODUCTION}

Recent publications have shown there is an increased interest amongst midwives about maternity care for asylum seeking and refugee women in the United Kingdom (UK) (Bennett and Scammell, 2014; McCarthy and Cooper, 2014; Thorogood, 2014). Contemporary society is characterised by an increasingly mobile global population (United Nations, 2014 a). Legislative changes relating to population movements, coupled with global economic policies and political instability across several continents, have resulted in an increase in the numbers of people migrating from their places of birth. In 2013 data from the United Nations Department of Economic and Social Affairs (UN-DESA) indicate that 232 million people currently live outside their country of origin (UN-DESA, 2014). Refugees and asylum seekers make up part of this wider migrant population. Refugees are defined by the United Nations (UN) as individuals who are outside their country of nationality "owing to a well-founded fear of being persecuted for reasons of race, religion, nationality, membership of a particular social group or political opinion... and are seeking in accordance with international conventions refuge in another country" (UNHCR, 1952: 14). Asylum seekers are individuals whose claims of refugee status have not been definitively decided by the country they seek refuge in (UN, 2014 b). The UN has estimated there to be more than 15 million refugees across the world. Four-fifths reside within low income counties (most commonly in countries adjacent to their countries of origin) whilst the other fifth seek refuge in higher income countries (UN, 2014 b). The economic, social and cultural impact of immigration has been a subject of concern for many high income migrant receiving counties.

Along with other European countries, immigration is the subject of intense political, ideological and cultural debate in the UK. This debate is linked to a range of global and national issues including concerns over; global terrorism and fundamentalism, the rise of far right political parties, issues of national identity, multiculturalism, ethnic/racial identity, economic challenges and resource allocation (Khosravinik, 2008). The dominant rhetoric surrounding immigration is overwhelmingly negative, particularly in relation to refugees or people seeking asylum. It deploys a range of discursive tropes including deserving and undeserving, health tourism, bogus asylum seekers, and being 'over run'. Many of these recall earlier iterations of anti-immigrant rhetoric and debate and all act to stigmatise and exclude (Mulvey, 2010; Duffy and Frere-Smith 2014). Alongside the rhetorical responses to immigration there have also been significant policy and legislative responses both in terms of seeking to restrict the number of immigrants who can enter the UK, and in regulating the lives of those who seek to remain in the UK. Zetter and others detail the "the intensifying spate of legislation... government white papers, consultation documents and reports" that have taken place since 1998 (Zetter et al., 2005: 70; Gower, 2014). 


\section{Immigration and health in the United Kingdom}

The health of those newly arrived in the UK has been an area of ongoing debate, particularly in terms of notions of health tourism and the financial implications of such. Research suggests that some new immigrants, particularly refugees and asylum seekers, experience high levels of mental and physical ill health. This is due to both the continuation of pre-existing health conditions ( Burnett and Peel, 2001; McColl et al., 2008) and as a result of the economic hardship, social deprivation and marginalisation experienced by refugees and asylum seekers once resident in the UK (BMA, 2002; Johnson, 2003; McColl et al., 2008; Burchill, 2011;Chantler, 2012). The situation is compounded by the substantial barriers faced by those newly arrived in the UK when seeking access to health care (Burnett and Peel, 2001; Drennan and Joseph, 2005; IOM, 2006; Kelley and Stevenson, 2006; MIND, 2009; British Red Cross, 2010; McCartney, 2010,). Research focusing on the health of asylum seeking and refugee women has demonstrated that these women, many of whom are of childbearing age, are disproportionally affected by health and social problems, placing them at greater risk of ill health (Maternity Action and Refugee Council, 2013, McCarthy and Haith-Cooper, 2013).

\section{Asylum seeking and refugee entitlements to maternity care}

In the UK maternity care is provided by the National Health Service (NHS) which provides free care at the point of delivery to all women based on a commitment to high quality universal provision, equality of access, and choice. Current policy recommends all "women, their partners, and their families are treated with equal importance and respect" (DOH, 2007: 2) and seeks to address the needs of women who face 'complex social factors' during pregnancy (NICE, 2010). Maternity care is free to all women who are 'ordinarily resident' in the UK. In addition, maternity care is considered, to be 'immediately necessary treatment' and so it cannot legally be refused to those who do not fit the residency criteria. Although a woman who is not considered to be lawfully resident in the UK may be asked to pay for treatment, all women who are refugees, or currently seeking asylum, or who have been refused asylum but are supported by the UK border agency, are eligible for free treatment (Maternity Action, 2014). Despite these statutory rights to access and a policy commitment to address issues of inequality, maternity services in the UK are failing to effectively reach and provide optimal care for asylum seeking and refugee women (Redshaw et al., 2006; Briscoe and Lavender, 2009; Médecins du Monde, 2009; Aspinall and Watter, 2010; Waugh, 2010; PICUM, 2011; De Lomba and Murray, 2014; Maternity Action, 2014). These women and their babies also face poorer outcomes in terms of higher rates of infant mortality (Taylor and Newall, 2008) and maternal mortality rates which are six times higher for newly arrived women than for long-term residents (Ibison et al., 1996; Lewis, 2004; Lewis, 2007).

\section{Non-statutory and voluntary sector support}

Much of the support afforded to refugee and asylum seekers within the UK comes from the nonstatutory or voluntary sector, who are either contracted by the government to provide these services, or operate independently as charities (McCarthy and Haith-Cooper, 2013). Workers from these 
organisations are considered to provide a vital safety net for refugees and asylum seekers in terms of mediating between their position of social exclusion and mainstream services (MIND, 2009; Flanagan and Hancock, 2010; Waugh, 2010). Despite the importance of the work done by these frontline workers in a range of settings including legal support, access to healthcare and help with housing and social support, there has been relatively little research undertaken to explore their experiences of working with childbearing refugee and asylum seeking women (Guhan and Liebling-Kalifani, 2011; Robinson, 2014).

This paper explores the activities and experiences of workers from the voluntary and non-statutory sector who support asylum seeking and refugee women during their pregnancy and early parenthood. It considers the impact of the asylum system on both the women whose daily lives are affected by their involvement in the system, as recounted by the volunteers who work with them, and on the workers themselves.

\section{METHODS}

The research reported here is part of a larger mixed method study designed to investigate access to maternity care amongst vulnerable women in the North West of England. The study was commissioned by the regional strategic health authority (SHA) which served a population of over $7,000,000$ people with a budget of over $£ 9.5$ billion. The larger project engaged with 23 primary care trusts, 26 acute hospital trusts and 416 Children's Centres providing maternity care and early years' provision for more than 85,000 births per annum across the North West (Downe et al., 2009).

\section{Ethics}

All necessary regulatory approvals were sought. Ethical approval was obtained from the School of Health Research Ethics Committee, University of Central Lancashire.

\section{Participants}

Following a quantitative telephone survey of professionals, refugee and asylum seeking women were identified as one of the groups that required more in-depth study. Given the difficulty of accessing these women directly, it was decided that the experiences of non-statutory workers who work directly with this client group would be explored. Local non-health sector groups and services with clientele who were likely to include pregnant refugee or asylum seeking women were approached to take part in the research. These groups and services included national organisations such as the British Red Cross, Connections and The Children's Society. Local community and church based organisations that provided support for a range of social welfare issues including destitution, mental health, housing and support for refugees and those seeking asylum were also approached. Managers within these organisations were asked to nominate staff (who had current or previous experience of providing support to pregnant women) who may be interested in attending a focus group. These individuals were then then given an 
"We make them feel special"

information sheet which contained the date, time and venue of the focus group. Ethical issues were discussed with potential participants in terms of the voluntary nature of participation, consent and confidentiality. As sensitive issues were likely to be discussed, confidentiality issues were agreed at the start of the discussion, and participants were asked to refrain from using individual names. Written consent was obtained from all participants. As one individual could not attend the group discussion but wished to participate in the study, a separate interview was organised. Overall a total of 19 individuals participated in three focus groups and one interview. These individuals included both paid and voluntary workers.

\section{Data Collection}

The focus groups were facilitated by two members of the research team, one led the discussion and one recorded field notes. Focus groups were chosen as a method of data collection as they provide the opportunity for the collection of rich data from a group of individuals and provide insights that may go beyond individual responses (Frey and Fontana, 1993). A semi-structured interview guide was designed to explore participant's perceptions of asylum seekers and refugee women's vulnerability, and the facilitators and barriers to these women's access to antenatal services. All data collection sessions were audio-recorded and transcribed verbatim with the accuracy of transcriptions checked by CK, KF and GT.

\section{Data analysis}

The audio-recordings were transcribed verbatim (MCB) who in conjunction with two other authors (SD and CK) undertook a three stage process of data analysis (Miles and Huberman, 1994). First, MCB commenced interactive reading and re-reading of the transcripts, beginning the process of getting to know the data in-detail. The second stage involved data reduction, display and interpretation of commonalities to identify emerging themes. As identified by Carter (2004), qualitative data analysis is systematic but rarely linear. Stage three involved theme building, the reintegration of context and verification of data relating to the unique vulnerability of asylum seeking and refugee women and the experiences and feelings of those working with refugee and asylum seeking women. The analysis was confirmed by the two other authors (GT and KF) to increase rigour.

\section{RESULTS}

Two principle themes emerged from the data which reflected the experiences of and role played by voluntary sector workers. The first principle theme 'literally through hell and back' concerned the unimaginable experiences of suffering, abuse and loss recounted by many of the women encountered by the volunteers and included two sub themes 'historical hell' and 'continuing hell'. The second principle theme 'bridging the unacknowledged gap' related to the invisible, unacknowledged processes undertaken by the volunteers of trying to negotiate a place for these unique and often hidden needs within the relatively rigid and exclusionary work-in-practice of current UK maternity services. This theme included two sub themes 'transience and lack of enculturation' and 'out of the box; care that bridges the gap'. 


\section{'Literally through hell and back'}

This theme encapsulates the negative experiences of women who have been forced to leave their countries of origin. The first sub theme 'historical hell' is illustrative of the social dislocation and personal suffering experienced as part of their journey to seek safety in the UK. The second sub theme 'continuing hell' considers how once the women arrive in the UK they faced 'continuing hell' as the asylum system exacerbated their difficulties.

(i) Historical hell

Many asylum seekers will instinctively feel vulnerable upon arrival in an alien country with a different language and unfamiliar customs (Burnett and Peel, 2001; Project London, 2006; MIND, 2009). Participants in the present study talked about the importance of recognising, acknowledging and supporting pre-existing vulnerabilities that pre-date arrival in the UK. Participants were mindful that women may have 'survived rape', have been exposed to persecution, oppression, 'torture and abuse' in their native country, and that some were fleeing from war torn environments where they had experienced the death or injury of family members. Sexual assault and rape are omnipresent considerations:

'We asked her why she was limping and she had been badly beaten. She had arrived I think 6 weeks earlier and she had survived rape.' (Focus group 2)

"Any vulnerable woman going through a pregnancy has got some major problems with being vulnerable, just being vulnerable but what we have got to understand or what the national health service has to understand [is] that as well as being pregnant and on your own, an asylum seeker has been through hell and back to get here literally hell and back."(Focus group 1)

(ii) Continuing hell

This sense of 'going through hell' does not stop with arrival in the UK, due to the legal and bureaucratic aspects of the asylum system. The participants explained how on arrival in the UK these women are immediately placed into a situation of uncertainty over their legal status and their ability to remain in the UK:

"These women are vulnerable because they are unsure of their status first and foremost." (Interview 1)

On arrival in the UK, these women, depending on their situation, may be given a range of legal statuses, all of which involve different rights and entitlements. For example, after seeking asylum some women may be given refugee status or granted 'leave to remain'. For these women the fear of immediate deportation is removed but they still face a range of uncertainties and challenges as they try to build lives in a new country. Other women may be refused asylum and so be 'denied leave to remain' and thus have 'no recourse to public funds'. These women are particularly vulnerable and are at high risk of destitution as they cannot receive statutory support until late in their pregnancy. One participant noted: 
"We make them feel special"

'There's one lady I am working with at the moment she has absolutely nothing. She's relying on charities and donations.' (Focus group 2)

Women also move between these statuses as they progress through the asylum system. This constant state of flux as well as fear of deportation was identified by participants as producing a state of constant uncertainty and instability for women. One worker described it as:

'Most refugees and asylum [seekers] are always on the move, it's like they are not settled emotionally and they are not settled physically and they are not settled socially.' (Interview 1)

A range of factors including; the compulsory dispersal of asylum seekers across the UK, housing policies that lead to no choice, poor quality accommodation and limited financial support mean that these women are positioned in situations of extreme vulnerability on the margins of mainstream society, both economically and socially. Participants described how women's complex and insecure lives became even more precarious during pregnancy:

'They are vulnerable because they are pregnant and they are not getting the support they need, they need medical attention; they are at risk of losing their home; they are stressed.' (Interview 1)

In addition many women had had negative experiences with statutory organisations and their personnel, both in their countries of origin, where these agencies may be complicit in their forced migration, and in the UK. For example, workers explained how women often experienced prejudicial attitudes from professionals:

'They are made to feel like they are like they are something they have wiped off their shoe and that's how the doctors speak to them,' (Focus group 1)

As a result women were often distrustful of establishing relationships with individuals from statutory organisations or with individuals they perceived to have positions of authority. One observed that, 'they don't think you are there for them, they think you are against them.' Participants spoke of how they attempted to support these women to move from this position of marginalisation where they faced significant barriers in accessing care, to a position where they could successfully receive support from the health and maternity care system. However, the difficulties these women and those who work with them faced were exacerbated by many statutory care-givers who displayed little understanding of the emotional, clinical, cultural and psycho-social needs of refugee and asylum seeking women. One participant explained this lack of understanding:

'I wonder if the doctors, nurses and maternity staff have any concept of that culture,' and that 'they need to understand that their culture is different to ours.' (Focus group 1)

As illustrated in the next theme, the volunteer workers acted to bridge this unacknowledged but very real gap, by providing alternative routes through which women in this situation can interact with the UK healthcare system. 
"We make them feel special"

\section{'Bridging the unacknowledged gap': the invisible role of voluntary sector workers}

The second principle theme was the role the workers played in 'bridging the unacknowledged gap' in service provision. It includes two related sub themes. The first, 'transience and lack of enculturation' relates to the workers experiences of the_multi-dimensional transience of refugee and asylum seeking women during pregnancy. It highlights the challenges they faced in ensuring that asylum seeking and refugee women were able to access the same levels of maternity care that UK residents are afforded. The second subtheme 'out of the box: care that bridges the gap', highlights how the volunteers believed they were in the best position to bridge the gap created by this transience and the subsequent lack of enculturalisation through using a range of innovative practices.

(i) Transience and lack of enculturation

Participants spoke of the challenges they encountered when working with pregnant refugee and asylum seeking women. The most significant of these were the complexity and instability surrounding the legal status of these women and the impact this had on their ability to access financial, housing, health and pregnancy related social support. The implications of this meant that women often accessed maternity care very late in their pregnancy and that voluntary agencies struggled to support women;

'If you are in the system if you are a refugee or an asylum seeker you will have some support, financial and accommodation support. If you are undocumented or you are somebody whose asylum claim has been failed, before you are $71 / 2$ months pregnant then you have no support. You are not under anybody's obligation to support and accommodate you until you are $71 \frac{1}{2}$ months pregnant. '(Focus group 2)

The impact of policies around dispersal and no choice accommodation related to women's legal status were also considered to negatively affect women's opportunities to build up important social support networks and limited the ability of the workers to provide continuity of care throughout the peri-natal period. One worker explained how one client was:

' [moved to] another house on her own because she needs more space, unfortunately through that 'generosity 'she is now completely isolated with no friends, nobody to look after the baby, she can't go to the shops, she doesn't know where the shops are anyway and so where is the social support?' (Focus group 1)

A further participant reported that the relocation of a woman meant that:

'There were not, you know cultural sort of things that she could engage with or even food and we tried so many times to move her a bit nearer ... where there would be better support networks for her but they [UK Border Agency] were not having it.' (Focus group 2)

The participants also reflected on another aspect of transience in relation to how women were passed between a range of different agencies with different philosophies, remits and boundaries; many of whom were reticent to take responsibility for meeting the women's needs, as is evident in the following account: 
"We make them feel special"

'[it was] quite difficult I think it was it was the authority that we sort of liaised with and they were saying we don't have any responsibility you need to speak to this person they said no you need to speak to the asylum team. She was at risk of becoming destitute. '(Focus group 2)

Participants repeatedly referred to a lack of cultural understanding and sensitivity in some areas of health and welfare provision. This lead to situations where women experienced inappropriate and inadequate care due to an expectation that they would 'fit in' to mainstream care:

'They have had to come over here and they don't speak the language, they don't know the system, they don't know the culture, nothing and they are expected to fit in just like that.' (Focus group 1)

Others identified how maternity care represented an 'alien concept' to women This meant that women often had no awareness of when and where to access care, the nature of ante-natal care and hospital birth as well as a lack of familiarity with early childcare practices seen as every day in the UK. One worker reported:

'They don't just need to be told this is what you do, you've got to show them and you have to understand they need to be shown. They have to understand their culture is different to ours and yes it might take the a bit longer to, the professionals a bit longer to explain it, but they still need. They don't have plastic bags, plastic nappy sacks and disposable nappies and you know plastic potties and dummies and baths and things. '(Focus group 1)

(ii) 'Out of the Box': care that bridges the gap

Despite the challenges and frustrations faced by the participants, they believed they provided invaluable support to the women during their pregnancy and early motherhood. They repeatedly expressed concern and care for the women, and employed a range of skills and approaches that, by their accounts, enabled women to receive the care they were entitled to. Participants demonstrated empathy for the women and showed an awareness of the difficulties they had faced on their journey to the UK and for the difficult situation they now found themselves in:

'And they have so much going on in their heads they are worried about being picked off at any time of the night and day by our government and they are worried about whether they are going to get asylum, they are worried about things that are happening in their country.' (Focus group 1)

They also repeatedly expressed concern that other agencies and individuals did not seem to appreciate these women's needs:

'Well yes you understand they have got targets to meet but people who are vulnerable ... perhaps actually need a bit more care. So you come home from hospital you get to see a midwife at x number of days afterwards, asylum seekers in the majority of cases are on their own, they are left with a tiny baby.'(Focus group 1) 
"We make them feel special"

Despite these difficulties participants acted to build trusting, compassionate and committed relationships with the women they worked with. Many participants stressed the need to see each woman as an individual and to "build up that relationship first so that they feel that they can trust you enough to open up," and how sensitivity was crucial to allow women to disclose potentially difficult issues such as rape or female genital mutilation. One male worker acknowledged the need for care in building relationships, particularly due to his gender:

'I've noticed that to be able to support that lady it's a matter of matter of building up over a period of time the word trust that XXXX used and being a man being careful not to intrude too much and to know when to back off, and things like that, and maybe let the female member of staff or worker support that person.' (Focus group 1)

Many of the workers spoke of their relationships with the women they supported in very personal terms. One explained how they:

'gather things together for them and we make them feel special, that mum is made to feel special and we make sure that when people go into hospital that they have someone to contact." (Focus group 1)

A number of workers spoke of the relationships they had developed with the women in terms of parenting. They acknowledged the women's lack of familial support, 'there is no mum here, an asylum seeker doesn't have a mum,' and explained how they were 'trying to help her like a maternal father would do,' or even how 'I am a mum to a lot of them.'

In order to ensure that the women they supported could access the care they needed the workers described how they had developed a range of alternative and innovative ways of working. One explained how caring for women necessitated:

'thinking a little bit outside the box instead of expecting everybody you know, to fit in ...cause these people will not... they cannot fit [into the box] 'cause they don't even know where the box is.' (Focus group 1)

In an attempt to overcome the poor attendance at mainstream maternity clinics they arranged to have clinics in a location already familiar to and trusted by the women and used workers already known to them:

'well we actually managed to have it here (community centre) and the success rate was brilliant, they came every week and they absolutely loved it ... and so they all came here and why did they come here, familiar building, welcoming.' (Focus group 1)

This was identified to have enabled more women to feel comfortable in accessing the services on offer. The workers also built on this by inviting other agencies to the community setting acknowledging that the women 'wanted to know all sorts of things.' They expanded the services they offered in that location to cover issues relating to healthy eating, dentistry and fire safety all of which allowed women to access a wider range of public health provision in a familiar environment. 
"We make them feel special"

Other pragmatic and innovative methods to overcome social isolation and language barriers were also employed. On one occasion a woman had been given a Dictaphone with a prerecorded message that could be played down the phone to the ambulance service once she went into labour:

"We had to tape record our voice on a Dictaphone, mention her name, [say] I'm pregnant or my labour has started this is my address please come."(Focus group 2)

Another example was when the workers made a woman practice saying "baby coming and her address." (Focus group 2)

The volunteers also encouraged and supported the development of social support networks through peer support provision. This was believed to be important to build on the resilience of the women and their communities by encouraging peer support among refugee, asylum seeking and other minority community women:

'We have got volunteers and we are trying to recruit more volunteers who would like to befriend someone for a period of time ... you know some of the mums who are expecting here, say a woman from Eritrea we might have a volunteer who is Eritrean who is just happy to you know go down to the house for a period of time.' (Focus group 1)

Participants frequently acted as advocates for the women they supported, for example, one described how they 'had been battling to get things changed.' In other situations participants negotiated with and between different agencies to try to ensure the women received the support they needed:

'There was a pregnant girl ....actually she was aged just 15 and they weren't going to give her any support and literally she [was] in hospital having the baby and I was still writing letters and you know on the phone you know threatening ... really angrily to NASS.' (Focus group 2)

\section{DISCUSSION}

The aim of this study was to investigate the roles and experiences of workers from the voluntary and non-statutory sector who support asylum seeking and refugee women during pregnancy and early parenthood in the UK. Much of the nature of the experiences of the volunteers was revealed through their perception of the experiences of the women they supported, and their emotionally nuanced accounts of these vicariously felt experiences, rather than in participant's direct accounts of what they did practically.

The findings of the study highlight the impact of both women's individual traumatic social histories, and the intransigence of the UK asylum system on the experiences of the women the workers supported and the impact this had on their ability to support and empower these women to access maternity care. These findings resonate with a number of existing reports in terms of how the current legislation perpetuates economic, social and cultural marginalisation (Sales, 2002; Healy, 2006; MIND, 2009), and 
creates negative physical and psychological implications for those who are already vulnerable (British Red Cross, 2010; Refugee Council, 2010; Asylum Aid, 2011; British Red Cross, 2014; Public Accounts Committee, 2014). The findings also resonate with issues raised by asylum seeking and refugee women's descriptions of their experiences of maternity care (Briscoe and Lavender, 2009; Hollowells, 2013; Maternity Action, 2013). This adds weight to our claim that these workers offer both key insights into the experiences of the women they work with and are ideally located to orchestrate changes to improve their access to UK maternity care. The research demonstrates how workers from voluntary and non-statutory agencies perceive themselves to play a crucial role in helping women negotiate the gap between an asylum system which limits the integration of individuals into mainstream British society, defining them as unwelcome temporary residents, and a maternity care system which stresses its commitment to inclusion and the rights of all women (Shimahara, 1970; MIND, 2009; Aspinal and Watter, 2010).

An important aspect of our findings relates to the concept of culture. Examples of cultural insensitivity to asylum seeking and refugee women were commonly reported by participants. This was compounded by the asylum seeking and refugee women's lack of knowledge of British culture and health and welfare systems. Enculturation is a crucial element of socialization into society. It is the process whereby humans learn the specificities of the culture of the society in which they reside (Shimahara, 1970). It is one of the many paradoxes of the current period of intense migration and intensification of worldwide social relations made possible by globalization and digital communications that divisions, diversity and inequalities are becoming more apparent between cultural groups not less (Wamala and Kawachi, 2007).

The challenges faced by the maternity care services to provide optimal maternity care for all women, particularly those with potentially complex health and social care needs remain significant. The impact of these challenges on maternal outcomes for some of these women has been highlighted in a number of studies (Francis et al., 2009; Phillimore, 2012) and the two most recent CEMACH reports (Lewis, 2007; Lewis, 2011). Lewis reported that black African women, especially those recently arrived in the UK, were nearly six times more likely to die than UK born white women (Lewis, 2007). In the same report, refugee and asylum seeking women made up $12 \%$ of all maternal deaths while being only $0.3 \%$ of the UK population. More recently, a local report identified that refugee and asylum seeking women made up $14 \%$ of maternal deaths while representing $0.5 \%$ of the population (City of Sanctuary, 2014).

There have been a number of studies which explore the maternity care experiences of asylum seeking and refugee women in the UK (McLeish 2002, Jentsch, 2007; Briscoe and Lavender, 2009; Hollowells, 2012; Maternity Action, 2013). However there has been little work done on the experiences of the midwives caring for these women. The research that has been done identifies a range of challenges faced by UK midwives who seek to provide high quality care for asylum seeking and refugee women. These include a lack of time, poor communication, the challenges of multi-agency practice, the stress of caring, lack of information and training, negative attitudes, as well as lack of continuity caused by dispersal and destitution (Bryant, 2011; Haith-Cooper and Bradshaw,2013; Bennett and Scammell, 2014; Thorogood, 2014). Other studies from Ireland and Norway report similar issues, which suggests 
these problems are not unique to the UK (Lyberg et. al., 2012;Tobin, 2014).This is the first study to explore the experiences and insights of non health care staff working in this area.

In the present study, participants identified how they were able to establish different relationships with the women they support, providing an additional level of social and practical support beyond that which can be provided by maternity and other health care workers. They undertake this work in difficult situations, often having to actively challenge prevailing cultural ideas and prejudices against their client group and working against a background of funding cuts and financial insecurity (Mafutala, 2010; HaithCooper and Bradshaw, 2013). At the same time it highlights the complimentary role that can be played by voluntary sector workers working alongside midwives, doctors and NHS maternity care as recommended in the NICE guidelines for pregnancy and complex social factors (NICE, 2010). They therefore appear to play a crucial role in supporting women in this situation by providing social and personal support that allows them to overcome the barriers they face in accessing care.

Study limitations relate to a small sample of participants recruited from one region in England. The generalisability of the findings is therefore based on the transferability of the theoretical findings, and not on assumptions of representativeness of the participants. The involvement of all authors in the analysis phase was used to increase rigor and the research was contextualized within a wider literature base.

\section{Recommendations for practice}

Insights from this study suggest that further research needs to be done with non-statutory workers and crucially with the women they support in order to explore the role they can play in facilitating the provision of high quality holistic support for these vulnerable women. Closer working relationships between the statutory and non-statutory or voluntary sectors when caring for the complex and health and social care needs of refugee and asylum seeking women would allow health care workers to better meet the needs of these women. Maternity care and other health services could benefit from integrating some of the innovative working practices developed by non-statutory workers. However more inclusive legislative change and health care reforms are needed if these women are ever to be able to receive equitable care and support from a health system that claims to provide "high quality care for all' (NHS England, 2015).

\section{Conclusion:}

Asylum seeking and refugee women have social histories that include experiences of extreme violence, and socio-cultural and linguistic dislocation. These are compounded by the enforced transience of such women when they encounter the UK asylum system. These women face unique challenges in accessing maternity services within the UK, which have serious negative implications for their physical and psychological wellbeing and for the health of their children. This research suggests that maternity services are currently struggling to fully meet the needs of these women whose lives are circumscribed 
by their position within the asylum system. The best intentions for the delivery of optimal care are also limited by a range of social, political and cultural factors which restrict the ability of pregnant and postnatal refugees and asylum seeking women to access and fully benefit from UK maternity care. Voluntary and non-statutory organisations and their staff working with this client group appear to undertake a vital but largely invisible role in bridging this gap through creating and sustaining positive relationships, providing social support and using highly creative and innovative strategies to overcome barriers and blocks to care.

\section{References}

Aspinall, P., Watter, C., 2010. Refugee and Asylum Seekers: A Review from Equality and Human Rights Perspective Equality and Human Rights Commission, London.

Asylum Aid., 2011. Unsustainable; quality of decision making in women's claims. Asylum Aid, London. Available from: (http://www.asylumaid.org.uk/wp-content/uploads/2013/02/unsustainableweb.pdf) (Accessed January 2015).

Briscoe, L., Lavender, T., 2009. Exploring maternity care for asylum seekers and refugees. British Journal of Midwifery 17:17-24.

British Medical Association., 2002. Asylum seekers: meeting their healthcare needs. British Medical Association, London.

British Red Cross., 2010. Not gone but forgotten the need for a more humane asylum system. British Red Cross, London.

British Red Cross., 2014. The Azure Card Report. British Red Cross, London. Available from:

(http://www.scribd.com/doc/234776188/Azure-Card-Report-2014 on 30/07/2014) (Accessed December 2014).

Bryant, H. B., 2011. Improving care for refugees and asylum seekers: The experiences of midwives. Maternity Action, London.

Burchill, J., 2011. Safeguarding Vulnerable Families: work with refugees and asylum seekers. Community Practitioner 84, 23-26.

Burnett, A., Peel, M., 2001. Asylum-seekers and refugees in Britain: health needs of asylum seekers and refugees. British Medical Journal 322, 544-7. 
"We make them feel special"

Carter, B., 2004. How do you analyse qualitative data. In: Lavender, T., Edwards, G., Alfirevic, Z. (Eds.), Demystifying Qualitative Research in pregnancy and Childbirth. Quay Books, Salisbury. 87-108.

Chantler, K., 2012. Gender, asylum seekers and mental distress: Challenges for mental health social work. British Journal of Social Work 42,318-334.

City of Sanctuary., 2014. City of Sanctuary Maternity Stream. Available from: (http://www.cityofsanctuary.org/maternity/about-maternity) (Accessed January 2015).

De Lomba, S., Murray, N., 2014. Women and Children First? Refused asylum seekers access to and experiences of maternity care in Glasgow. University of Strathclyde and the Refugee Council, Glasgow.

Department of Health., (DOH), 2007. Maternity Matters: choice, access and continuity of care in a safe service. Department of Health, London.

Downe, S., Kingdon, C., Finlayson, K., et al., 2009. Hard to reach? Access to Maternity Services for 'Vulnerable' Women in the North West Project Report .University of Central Lancashire, Preston. Available from: http://www.chimat.org.uk/resource/item.aspx?RID=85865) (Accessed November 2014).

Drennan, V.M., Joseph, J.2005. Health Visiting and Refugee Families: issues in professional practice. Journal of Advanced Nursing 49,155-163.

Duffy B, Frere-Smith T., 2013. Perceptions and Reality: Public Attitudes to Immigration. IPSOS/MORI, London. Available from: (http://www.ipsos-mori.com/DownloadPublication/1634 sri-perceptionsandreality-immigration-report-2013.pdf) (Accessed January 2015).

Flanagan, S. M., Hancock, B., 2010. Reaching the hard to reach; lessons learned from the VCS (voluntary and community sector) A qualitative study. BMC Health Services Research 10, 92.

Francis, A., Elsheikh, A., Gardesi, J., 2009. Still births, infant deaths and social deprivation in the West Midland 1997 to 2007/8.University of Birmingham, Birmingham.

Frey, J., Fontana, A., 1993. The group interview in social research. In: Morgan, D. (Ed.), Successful Focus Groups: Advancing the State of the Art. Sage, Newbury Park, CA.20-34.

Gaaserud, A., 2001. Maternity services for newly-arrived refugee and asylum seeking women in the City and Hackney boroughs of London. City and Hackney Primary Care Trust, London.

Gower, M., 2006. Organisational reforms to the immigration system since 2006 Standard Note: SN/HA/6719 House of Commons library, London. Available from: (file://C:/Documents\%20and\%20Settings/Administrator/My\%20Documents/Downloads/SN06719.pdf) (Accessed November 2014). 
"We make them feel special"

Guhan, R., Liebling-Kalifani, H., 2011. The Experiences of Staff Working With Refugees and Asylum Seekers in the United Kingdom: A Grounded Theory Exploration. Journal of Immigrant \& Refugee Studies 9, 205-228.

Haith-Cooper, M., Bradshaw, G., 2013. Meeting the health and social needs of pregnant asylum seekers, midwifery students' perspectives: part 1 ; dominant discourses and midwifery students. Nurse Education Today 33:9,1008-1013.

Healy, R.L., 2006. Asylum seekers and refugees: A Structuration Theory Analysis of their experiences in the UK. Population, Place and Space 12,257-271.

Hollowells, J., Oakley, L., Vigurs, C., et al., 2012. Increasing the early initiation of antenatal care by Black and Minority Ethnic women in the United Kingdom: a systematic review and mixed methods synthesis of women's views and the literature on intervention effectiveness. Oxford: National Perinatal Epidemiology Unit. Available from: (https://www.npeu.ox.ac.uk/downloads/files/infant-mortality/Infant-Mortality--DIVA-final-report-Oct-2012.pdf) (Accessed August 2015).

Ibison, J. M., Swerdlow, A. J., Head, J. A. M., Marmot M., 1996. Maternal Mortality in England and Wales 1970-1985: An analysis by country of birth. British Journal of Obstetrics and Gynaecology 103,973-980.

International Organisation for Migration (IOM)., 2006. Maternal and Child Healthcare for Immigrant Populations. International Organisation for Migration, Brussels.

Johnson, M., 2003. Asylum Seekers in Dispersal - Healthcare issues. Home Office, London. Available from: (http://www.nrac.scot.nhs.uk/wpcontent/uploads/docs/NHS Boards/Glasgow/Asylum\%20seekers\%20in\%20dispersal\%20\%20healthcare\%20issues.pdf) (Accessed November 2014).

Kelley, N., Stevenson, J., 2006. First do no harm: Denying health care to people whose asylum claims have failed. Refugee Council, London.

Khosravinik, M., 2008. British Newspapers and the Representation of Refugees, Asylum Seekers and Immigrants between 1996 and 2006. Working Paper No. 128. Working Papers Series Lancaster University Department of Linguistics and English Language, Lancaster. Available from: (http://www.ling.lancs.ac.uk/groups/clsl/docs/clsl128.pdf) (Accessed December 2014).

Lewis, G., 2004. Confidential enquiry into maternal and child health: Why mothers die 2000-2002: The Sixth report of confidential enquiries into maternal deaths in the United Kingdom. CEMACH, London.

Lewis, G., 2007. Confidential Enquiry into Maternal and child health Saving Mothers lives: reviewing maternal deaths to make motherhood safer 2003-2005 The seventh report on confidential enquiries into maternal deaths in the United Kingdom. London: CEMACH, London. 
"We make them feel special"

Lewis, G., 2011. The Eighth Report on Confidential Enquiries into Maternal Deaths in the United Kingdom. British Journal of Obstetrics \& Gynaecology 118, 1-203.

Lyberg, A., Viken, B., Haruna, M., Severinsson, E., 2012. Diversity and challenges in the management of maternity care for migrant women. Journal of Nursing Management 20. 287-295.

Maternity Action., Refugee Council., 2013. When Maternity doesn't matter: dispersing pregnant women seeking asylum. Maternity Action, London.

Maternity Action., 2014. Entitlement to free NHS maternity care for women from abroad. Available from:( http://www.maternityaction.org.uk/wp/advice-2/mums-dads-scenarios/3-women-fromabroad/entitlement-to-free-nhs-maternity-care-for-women-from-abroad/) (Accessed December 2014).

Mafutala, J.P., 2010.Refugee Council Briefing: The impact of spending cuts on refugee community organisations. Refugee Council, London.

McColl, H., McKenzie, K., Bhui, K., 2008. Mental healthcare of asylum-seekers and refugees. Advances in Psychiatric Treatment 14,452-459.

Médecins du Monde., 2009. Access the Healthcare for undocumented migrants in 11 European Countries. Médecins du Monde European Observatory on access the healthcare. Available from: (http://mdmgreece.gr/attachments/283 huma\%20en.pdf) (Accessed January 2015).

Miles, M.B., Huberman, A. M., 1994. Qualitative Data Analysis: An Expanded Sourcebook. 2nd Edition. SAGE Publications, London.

MIND., 2009. A civilized Society: mental health provision for refugees and asylum seekers in England and Wales. MIND, London.

Mulvey, G., 2010. When policy creates politics: The problematizing of immigration and the consequences for refugee integration in the UK. Journal of Refugee Studies 23,437-62.

McCartney, M., 2010. Poor diagnosis for Asylum seekers health needs. British Medical Journal 341, 4106.

McCarthy, R., Haith-Cooper, M., 2013. Evaluating the impact of befriending for pregnancy asylum seeking and refugee women. British Journal of Midwifery 21, 276-281.

McLeish, J., 2002. Mothers in Exile: Maternity experiences of asylum seekers in England. Maternity Alliance, London.

NHS England., 2015. Implementing our mission; high quality care for all. Available from: (http://www.england.nhs.uk/about/imp-our-mission/) (Accessed February 2015). 
"We make them feel special"

Redshaw, M., Rowe, R., Hockle, C., Brocklehurst, P, 2006. Recorded Delivery: A national Survey of Women's experiences of maternity care. Available from:(

http:www.npeu.ox.ac/recordeddelivery)(Accessed January 2015)..

NICE., 2010. Pregnancy and complex social factors: A model for service provision for pregnant women with complex social factors. NICE Guidelines CG110. Available from:

(https://www.nice.org.uk/guidance/cg110)(Accessed December 2014).

Project London., 2006. Helping Vulnerable People to access healthcare Report. Project London, London.

Platform for International Cooperation on undocumented migrants (PICUM)., 2011. Preventing Undocumented Women and Children from Accessing healthcare: Fostering Health Inequalities in Europe. PICUM, Brussels. Available from:( http://picum.org/en/publications/conference-and-workshopreports/25872/) (Accessed January 2015).

Phillimore, J., 2012. Evidence for the House of Commons Inquiry into Asylum Support for Children and Young People. Available from:

(http://www.childrenssociety.org.uk/sites/default/files/tcs/Policy/asyluminquiry/dr jenny phillimore.pdf) (Accessed November 2014).

Public Accounts Committee., 2014. 54th Report, COMPASS: provision of asylum accommodation. London. Available from:( http://www.parliament.uk/business/committees/committees-a-z/commonsselect/public-accounts-committee/news/asylum-accommodation-substantive/) (Accessed December 2014).

Robinson, K., 2014. Voices from the front line: Social work with refugees and asylum seekers in Australia and the UK. British Journal of Social Work 44, 1602-1620.

Refugee Council., 2010. Not a minor offence, children in detention. Refugee Council, London.

Sales, R., 2002. The deserving and the undeserving? Refugees, asylum seekers and welfare in Britain. Critical Social Policy 22, 456-478.

Shimahara, N., 1970. Enculturation-a reconsideration. Current Anthropology 11,143-154.

Taylor, B., Newall, D., 2008. Maternity, mortality and migration: the impact of new communities. Heart of Birmingham Teaching Primary Care Trust \& West Midlands strategic migration partnership, Birmingham.(Available from:

(http://www.wmemployers.org.uk/media/upload/Library/Migration\%20Documents/Publications/MMM Document FINAL Webversion.pdf)(Accessed January 2015).

Thorogood, V., 2014. Doing our best for women seeking asylum. The Practicing Midwife 17(1), 17-19.

Tobin, C. L., Murphy-Lawless, J., 2014. Irish midwives' experiences of providing maternity care to nonIrish women seeking asylum. International Journal of Women's Health6, 159-169. 
"We make them feel special"

United Nations (UN)., 2014. a. United National Global Migration Database. Available from: (http://esa.un.org/unmigration/) (Accessed February 2015).

United Nations (UN)., 2014. b. refugees/ forced displacement over view. Available from: (http://www.un.org/en/globalissues/briefingpapers/refugees/overviewofforceddisplacement.html) (Accessed January 2015).

United Nations Department of Economic and Social Affairs (UN-DESA)., Number of international migrants rises above 232 million. Available from:

(http://www.un.org/en/development/desa/news/population/number-of-international-migrantsrises.html) (Accessed January 2015).

United Nations High Commission for Refugees (UNHCR)., 1952 Refugee convention. Available from: (http://www.unhcr.org/pages/49c3646c137.html) (Accessed December 2014).

Wamala, I., Kawachi, S., 2007. Globalization and Health. OUP, New York, USA.

Zetter, R., Griffiths, D., Sigona, N., 2005. Social capital or social exclusion? The impact of asylum seeker dispersal on refugee community organisations. Community Development Journal 40, 69-81. 